\title{
Two-Dimensional Finite Element Method Analysis Effect of the Recombination Velocity at the Grain Boundaries on the Characteristics of a Polycrystalline Silicon Solar Cell
}

\author{
Nzonzolo', Désiré Lilonga-Boyenga1, Camille Nziengui Mabika1, Grégoire Sissoko² \\ ${ }^{1}$ Electronics and Electrical Engineering Laboratory, Polytechnic Superior National School, University Marien Ngouabi, Brazzaville, \\ Republic of the Congo \\ ${ }^{2}$ Laboratory of Semiconductors and Solar Energy, Physics Department, Faculty of Science and Technology, University Cheikh Anta Diop, \\ Dakar, Senegal \\ Email:nzonzolo@gmail.com, lilongadesire@yahoo.fr
}

How to cite this paper: Nzonzolo, LilongaBoyenga, D., Mabika, C.N. and Sissoko, G. (2016) Two-Dimensional Finite Element Method Analysis Effect of the Recombination Velocity at the Grain Boundaries on the Characteristics of a Polycrystalline Silicon Solar Cell. Circuits and Systems, 7, 4186-4200. http://dx.doi.org/10.4236/cs.2016.713344

Received: May 10, 2016

Accepted: May 30, 2016

Published: November 18, 2016

Copyright $\odot 2016$ by authors and Scientific Research Publishing Inc. This work is licensed under the Creative Commons Attribution International License (CC BY 4.0).

http://creativecommons.org/licenses/by/4.0/

\begin{abstract}
To take into account the variation of the recombination velocity at the grain boundaries, we present in this paper a new approach of characterization of the solar cells, based on the two dimensional finite element method. The results of this study on a bifacial polycrystalline silicon solar cell, modelled in the rectangular form, highlighting the effects of the boundary recombination velocity $\left(S_{g b}\right)$ on the solar cell electrical parameters. The photogenerated excess carrier's density, the photocurrent density; the phototovoltage and the current-voltage characteristics are analyzed, namely. A good agreement with the results given in the literature is observed.
\end{abstract}

\section{Keywords}

Solar Cell, Grain Boundary, Photocurrent, Photovoltage, Recombination Velocity, Finite Element

\section{Introduction}

To characterize solar cells, several studies, based for their majority on analytical methods, have been carried out in one dimension, two dimensions, or three dimensions [1] [2] [3] [4] [5]. These studies have permitted to characterize polycrystalline solar cells by determining the effects of the grain size and the recombination velocities for example, on the phenomenological and electrical parameters of the solar cell [1] [6] [7] [8]. The illumination level and 
the current-voltage characteristics were also studied [9] [10]. Unfortunately, each study required to carry out specific calculations according to the problem to be solved.

The objective of this study is to present a new approach of characterization of the solar cells, based on the finite element method. Using this method, the continuity equation in two dimensions can be solved, by modeling the crystal of a solar cell in 2D.

Compared to the analytical methods, in this approach, the results are obtained without redundancies of calculations for the various characteristics of the solar cell. In this study, we propose, for various values of the boundary recombination velocity $S_{g b}$, to determine the excess photogenereted carrier's density, as well as the photocurrent density, the photovoltage and the current-voltage characteristics of the polycrystalline solar cell in the case where the thickness of the crystal solar cell is negligible comparatively to its width and its depth.

\section{Theoretical Analysis}

Let us consider a rectangular bifacial crystalline silicon solar cell having a base depth $H_{1}$ and a width $H_{2}$, illuminated successively on its front surface and on its back surface as represented in Figure 1.

One supposes moreover that no external electric or magnetic field is applied to the structure and the semiconductor substrate used is a thin layer, hence the effect of its thickness on the dynamics of the carriers is negligible.

In this case, the continuity equation which governs the solar cell's operation is given by the following relation [1]:

$$
\frac{\partial^{2} \delta(x, y)}{\partial x^{2}}+\frac{\partial^{2} \delta(x, y)}{\partial y^{2}}-\frac{\delta(x, y)}{L^{2}}=-\frac{g(x, y)}{D}
$$

where $\delta(x, y)$ represents the photogenereted excess minority carrier's density in the base, $L$, the diffusion length, $D$, the coefficient of diffusion and $g(x, y)$, the rate of generated carriers.

If this rate of generation depends only on $x[1]$, we have:

$$
g(x)=\left\{\begin{array}{l}
\sum_{1}^{3} a_{i} \cdot \exp \left(-b_{i} x\right) \text { for the front surface illumination } \\
\sum_{1}^{3} a_{i} \cdot \exp \left(-b_{i}(H-x)\right) \text { for the back surface illumination }
\end{array}\right.
$$

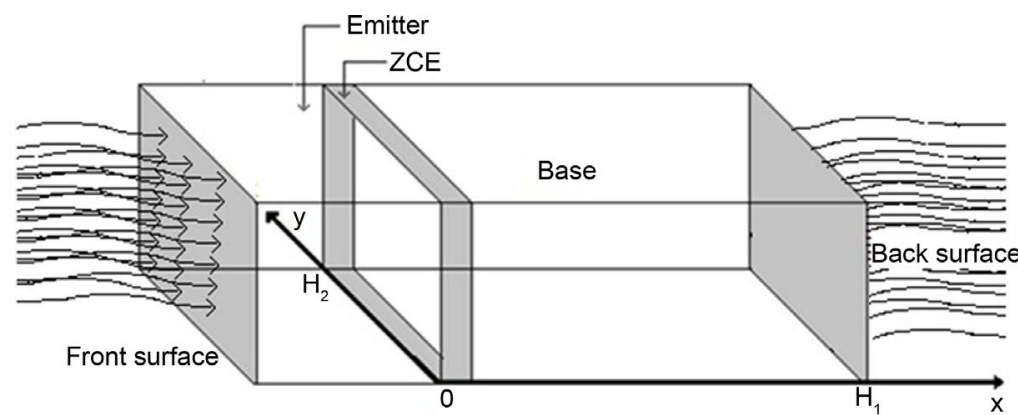

Figure 1. Bifacial silicon solar cell. 
The parameters $a_{i}$ and $b_{i}$ are the constants deduced from the modeling of the generation rate considered for the overall solar radiation spectrum [10].

The continuity Equation (1) obeys to the following boundary conditions [1], namely, the current of diffusion and the current of recombination are equal on the boundaries, i.e.:

- on the junction $x=0$

$$
\left.\frac{\partial \delta(x, y)}{\partial x}\right|_{x=0}=\frac{S_{j}}{D} \cdot \delta(0, y)
$$

- on the back surface

$$
\left.\frac{\partial \delta(x, y)}{\partial x}\right|_{x=H_{1}}=-\frac{S_{b}}{D} \cdot \delta\left(H_{1}, y\right)
$$

- on the $y=0$ boundary

$$
\left.\frac{\partial \delta(x, y)}{\partial x}\right|_{y=0}=\frac{S_{g b}}{D} \cdot \delta(x, 0)
$$

- on the $y=H_{2}$ boundary.

$$
\left.\frac{\partial \delta(x, y)}{\partial x}\right|_{y=H_{2}}=-\frac{S_{g b}}{D} \cdot \delta\left(x, H_{2}\right)
$$

$S_{j}$ indicates the junction recombination velocity, $S_{b}$ the back surface recombination velocity, and $S_{g b}$, boundary recombination velocity on the boundaries $y=0$ and $y=H_{2}$.

This continuity equation is an elliptic differential equation with Neumann boundaries conditions [11]. It can be written to the following general form:

$$
-\nabla(c \nabla u)+\beta \cdot u=f
$$

The associated Neumann's boundary conditions are:

$$
\begin{aligned}
& u^{\prime}(0, y)=a \cdot u(0, y) \\
& u^{\prime}(H, y)=b \cdot u(H, y) \\
& u^{\prime}(x, 0)=c_{1} \cdot u(0, y) \\
& u^{\prime}\left(x, H_{1}\right)=c_{2} \cdot u\left(x, H_{1}\right)
\end{aligned}
$$

where $c=1, \quad \beta=\frac{1}{L^{2}}, u=\delta(x, y)$ and $f=\frac{g(x)}{D}$.

\subsection{Variational Formulation and Discretization of the Equation}

The variational form associated with Equation (7) is:

$$
\int_{\Omega}(\nabla u \cdot \nabla v) \mathrm{d} x \mathrm{~d} y+\int_{\Omega} \beta u v \mathrm{~d} x \mathrm{~d} y-\int_{\Gamma} \boldsymbol{n} \cdot(\nabla u) v \mathrm{~d} s-\int_{\Omega} f v \mathrm{~d} x \mathrm{~d} y=0
$$

where $\boldsymbol{n}$, is the normal unit vector on the border $\Gamma$ and $\boldsymbol{n}(\nabla)=\frac{\partial}{\partial n}$, a normal derivative on this border. To solve Equation (9), one subdivides the domain $\Omega$ delimited by $x$ $=0$ and $x=H_{1}$ according to $O x$ and $y=0 y=H_{2}$ according to $O y$, into 
$2\left(N_{1}-1\right) *\left(N_{2}-1\right)$ triangular finite elements where $N_{1}$ and $N_{2}$ are positive integers. One has $N_{1} \times N_{2}$ points for the mesh, as represented in Figure 2(a).

Let us consider a triangular finite element e and its three vertices 1, 2 and 3 with their respective coordinates $\left(x_{1}, y_{1}\right),\left(x_{2}, y_{2}\right)$ and $\left(x_{3}, y_{3}\right)$, as shown in Figure 2(b).

In this element $e, u(x, y)$ can be approximated by a continuous solution $u_{e}(x, y)$ hence the approximate solution on whole domain $\Omega$ is given by [12].

$$
u(x, y) \approx \sum_{e=1}^{m} u_{e}(x, y)
$$

$m$ being the number of triangular finite elements of discretization.

For triangular finite elements, $u_{e}(x, y)$ can be seeking in the linear form:

$$
u_{e}(x, y)=a+b x+c y
$$

After eliminating the constants $a, b$ and $c$ in above Equation (10), one obtains the carrier's density of finite element $e$ as follows:

$$
u_{e}(x, y)=\sum_{i=1}^{3} \alpha_{i}(x, y) u_{e i}
$$

where $\left(u_{e 1}, u_{e 2}, u_{e 3}\right)$ indicate the values of carrier's density at the vertices $(1,2,3)$ and $\alpha_{i}(x, y)$ the coefficients given by:

$$
\left\{\begin{array}{l}
\alpha_{1}=\frac{1}{2 A_{e}}\left[\left(x_{2} y_{3}-x_{3} y_{2}\right)+\left(y_{2}-y_{3}\right) x+\left(x_{3}-x_{2}\right) y\right] \\
\alpha_{2}=\frac{1}{2 A_{e}}\left[\left(x_{3} y_{1}-x_{1} y_{3}\right)+\left(y_{3}-y_{1}\right) x+\left(x_{1}-x_{3}\right) y\right] \\
\alpha_{3}=\frac{1}{2 A_{e}}\left[\left(x_{1} y_{2}-x_{2} y_{1}\right)+\left(y_{1}-y_{2}\right) x+\left(x_{2}-x_{1}\right) y\right]
\end{array}\right.
$$

$A_{e}$ is the surface of triangular element such as:

$A_{e}=\frac{1}{2}\left[\left(x_{2}-x_{1}\right)\left(y_{3}-y_{1}\right)-\left(x_{1}-x_{3}\right)\left(y_{1}-y_{2}\right)\right]$.

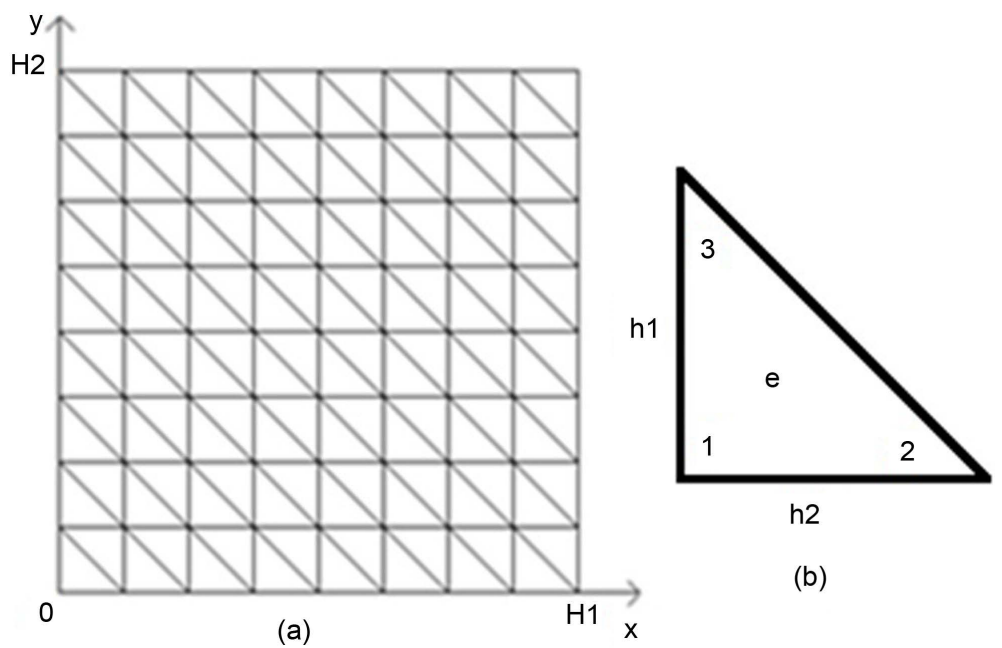

Figure 2. (a) Two-dimensional discretization of the solar cell crystal, (b) triangular finite element $e$. 
In each element, if one chooses $v_{e}(x, y)=\sum_{i=1}^{3} \alpha_{j}(x, y) u_{e j}$ as a trial function, these expressions of $u_{e}$ and $v_{e}$ introduced in the Equation (9) leads to the relation:

$$
A^{(e)} U^{(e)}=L^{(e)}
$$

where $U^{(e)}=\left[u_{e 1}, u_{e 2}, u_{e 3}\right]$ and $A^{(e)}=M^{(e)}+T^{(e)}+Q^{(e)}$.

The elements of the matrix $M^{(e)}$ (Stiffness matrix) are given for each triangular element by the integral [12]:

$$
M_{i j}^{e}=\int \nabla \alpha_{i} \nabla \alpha_{j} \mathrm{~d} s
$$

Those of the mass matrix $T^{(e)}$ are determined by:

$$
T_{i j}^{e}=\int \beta \alpha_{i} \alpha_{j} \mathrm{~d} x \mathrm{~d} y
$$

The elements of the matrix $Q^{(e)}$, taking account of the boundary conditions and the orientation of the normal vector $\boldsymbol{n}$, on the borders, are given by:

$$
\begin{gathered}
M_{i j}^{e}-\int_{\Gamma} \boldsymbol{n} \cdot\left(\nabla \alpha_{i}(x, y)\right) \alpha_{j}(x, y) \mathrm{d} s \\
\mathrm{~d} s=\left\{\begin{array}{l}
\mathrm{d} y \text { at the boundaries } x=0 \text { et } x=H_{1} \\
\mathrm{~d} x \text { at the boundaries } y=0 \text { et } y=H_{2}
\end{array}\right.
\end{gathered}
$$

$L^{(e)}$ is a column matrix representing the second member. Its elements are given by:

$$
L_{i}^{e}=\int f \alpha_{i}(x, y) \mathrm{d} x \mathrm{~d} y
$$

Taking into account the contribution of each triangular element, one obtains the carriers density $U$ to each node of the mesh after assembling all of the matrices $A^{e}$ and et $L^{e}$. Thus this carrier's density, after minimization of the variational form (9), obeys to the equation:

$$
A \boldsymbol{U}=\boldsymbol{L}
$$

or inversely:

$$
\boldsymbol{U}=\boldsymbol{A}^{-1} \boldsymbol{L}
$$

$A$ and $L$ are the global matrix of Equation (13). The vector $\boldsymbol{U}=\left[u_{1}, u_{2}, u_{3}, \cdots, u_{N_{1} \times N_{2}}\right]^{\mathrm{T}}$ is the unknown excess minority carrier's density.

\subsection{Current-Voltage Characteristics of the Solar Cell}

By considering that the minority carriers flow in y-direction is weak compared to that in $\mathrm{x}$-direction, the current-voltage characteristic of the solar cell is obtained by determining the photocurrent density $J$ and the photovolatge $V$ calculated from the relations (21) and (22) respectively as follow [1] [3]:

$$
J=\frac{q \cdot D}{H_{2}} \int_{0}^{H_{2}}\left[\frac{\partial \delta(x, y)}{\partial x}\right]_{x=0} \mathrm{~d} y
$$

$q$ indicates the electron's charge and

$$
V=V_{T} \cdot \log \left(\frac{N b}{n_{i}^{2}} \int_{0}^{H_{2}} \delta(0, y) \mathrm{d} y+1\right)
$$


$V_{T}$, represents the thermal voltage, $N b$ : the doping in the base, $n_{i}$, the intrinsic carrier's concentration.

\section{Results and Discussions}

\subsection{Convergence Study}

Using a numerical code that we conceived from this theoretical approach based on the finite element method, we have solved the continuity equation and analyzed the effects of recombination velocity at the grains boundary on the electric parameters of the solar cell. To validate our results, we initially determined the number of finite elements of the grid beyond that the solution converges. Thus, we have plotted in Figure 3, the minority carriers density photogenerated at the $y=0$ plane boundary, for various values of the number of finite elements with $N_{1}=N_{2}=N$.

These curves shows that the convergence of the solution is obtained when $N \geq 30$ i.e. for 1682 finite elements and 900 points of the mesh.

To ensure a good compromise between the precision and the computing time, we chose to use $N=30$ finite elements.

\subsection{Minority Carrier's Density}

We represented in Figure 4 and Figure 5, the excess minority carriers density according to base depth $x$, and the grain width $y$, when the solar cell is respectively illumination on its front surface and its back surface.

One notes that for the front surface illumination, the carriers density increases according to $X$, reaches its maximum around $x=0.175 \mathrm{~mm}$, then it decreases and cancels when $x=0.3 \mathrm{~mm}$. As for illumination on the back surface of the solar cell, the curve

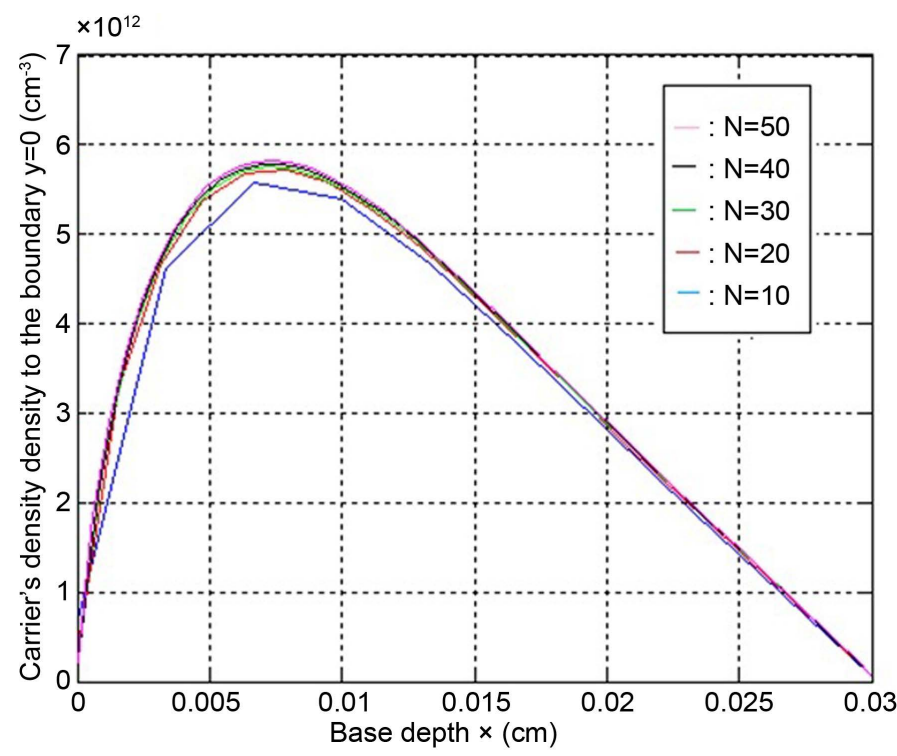

Figure 3. Minority carrier's density to the plane $\mathrm{y}=0$ boundary, for various values of $N$ with $D=26 \mathrm{~cm}^{2} / \mathrm{s}, L=0.01 \mathrm{~cm}, S_{j}=10^{6} \mathrm{~cm} / \mathrm{s}, S_{b}=$ $10^{5} \mathrm{~cm} / \mathrm{s}, S_{g b}=10^{2} \mathrm{~cm} / \mathrm{s}$. 


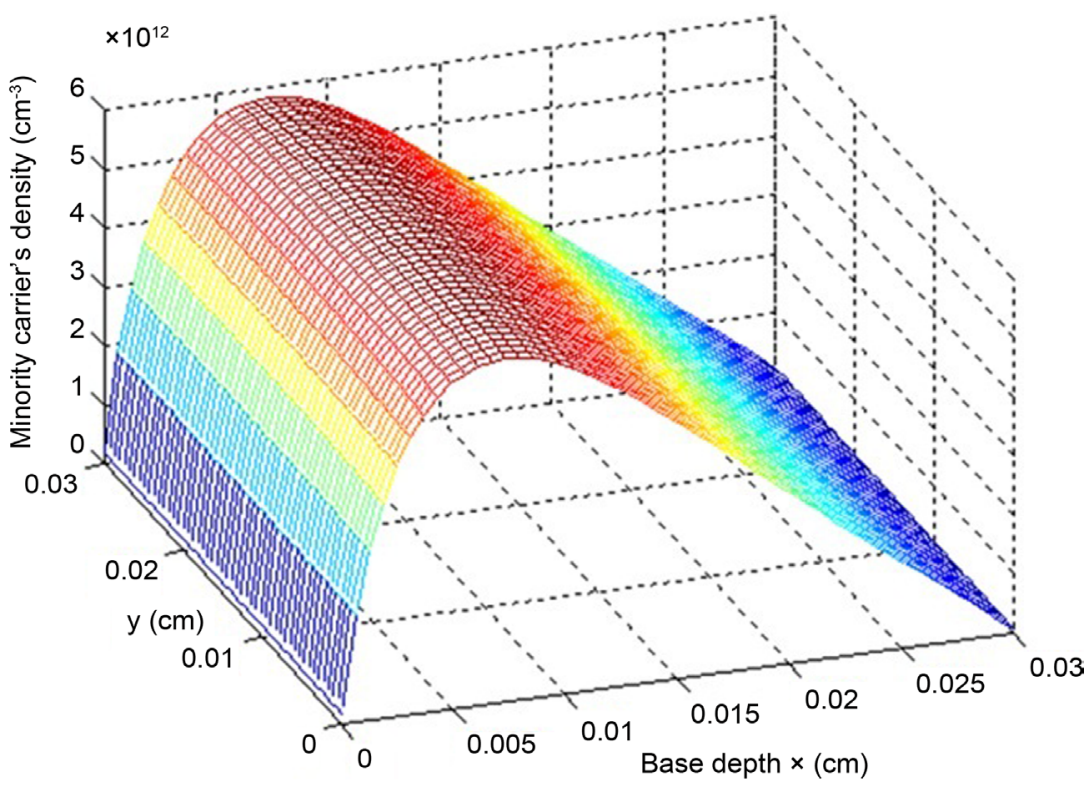

Figure 4. Minority carrier's density, front surface illumination: $D=26 \mathrm{~cm}^{2} / \mathrm{s} ; L=$ $0.01 \mathrm{~cm} ; S_{j}=10^{6} \mathrm{~cm} / \mathrm{s} ; S_{b}=10^{5} \mathrm{~cm} / \mathrm{s} ; S_{g b}=10^{2} \mathrm{~cm} / \mathrm{s}$.

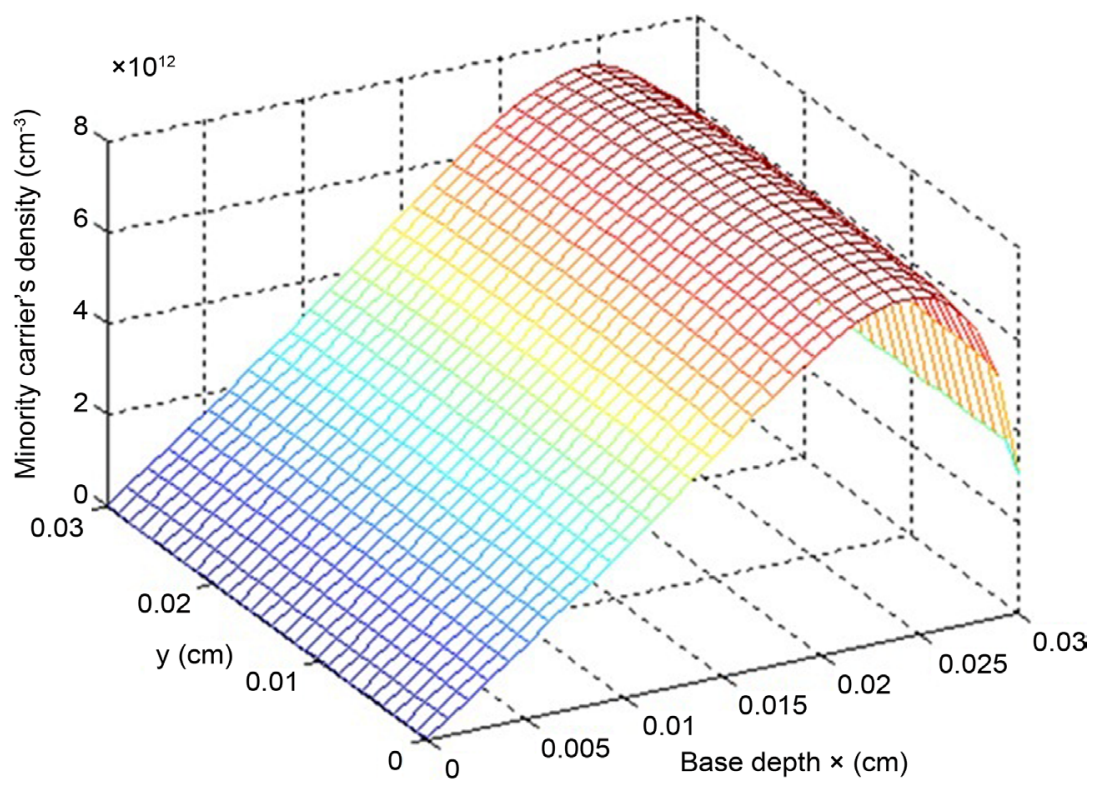

Figure 5. Minority carrier's density, back surface illumination: $D=26 \mathrm{~cm}^{2} / \mathrm{s} ; L=$ $0.01 \mathrm{~cm} ; S_{j}=10^{6} \mathrm{~cm} / \mathrm{s} ; S_{b}=10^{5} \mathrm{~cm} / \mathrm{s} ; S_{g b}=10^{2} \mathrm{~cm} / \mathrm{s}$.

preserves the same profile but the maximum is reached around $x=0.25 \mathrm{~mm}$.

We can also note a slight variation of these densities according to $y$, for both illuminations.

The effect of grain boundary recombination velocity on the minority carrier's density is highlighted in Figures 6-9.

The grain boundary recombination velocity $S_{g b}$, reveals the carriers losses by recombination, at the grains boundaries. These losses significantly influence the profile of the 


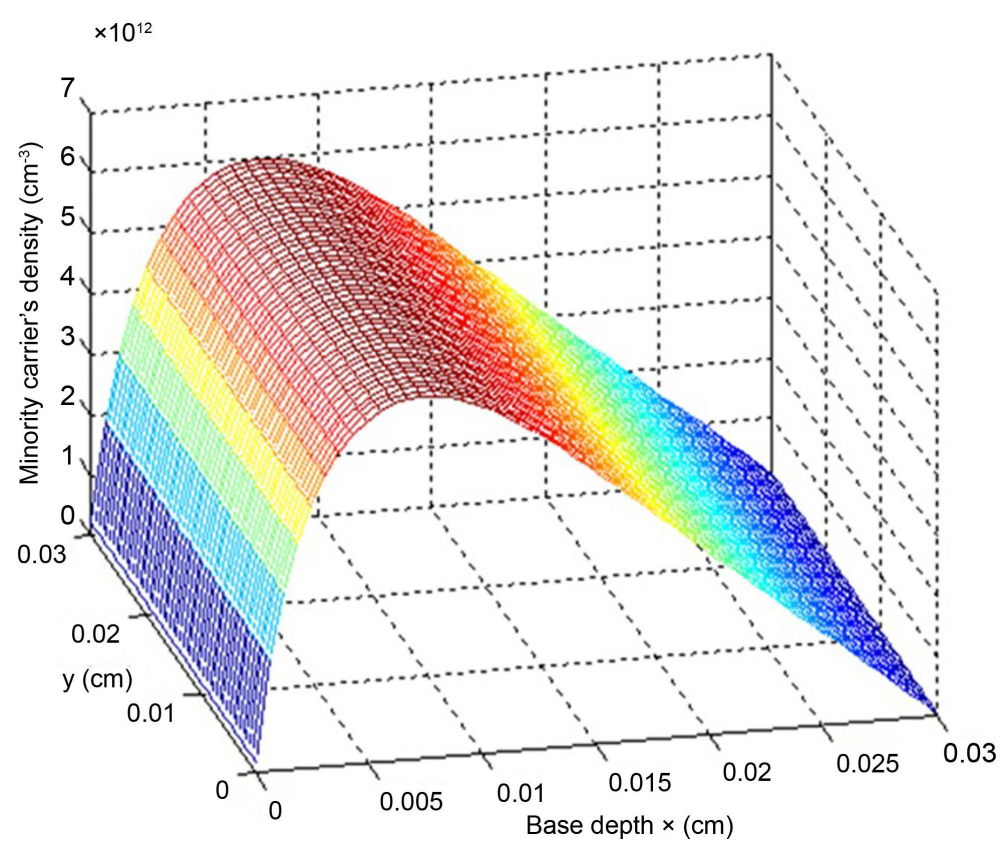

Figure 6. Minority carrier's density, front surface illumination: $D=26 \mathrm{~cm}^{2} / \mathrm{s}$; $L=0.01 \mathrm{~cm} ; S_{j}=10^{6} \mathrm{~cm} / \mathrm{s} ; S_{b}=10^{5} \mathrm{~cm} / \mathrm{s} ; S_{g b}=0$.

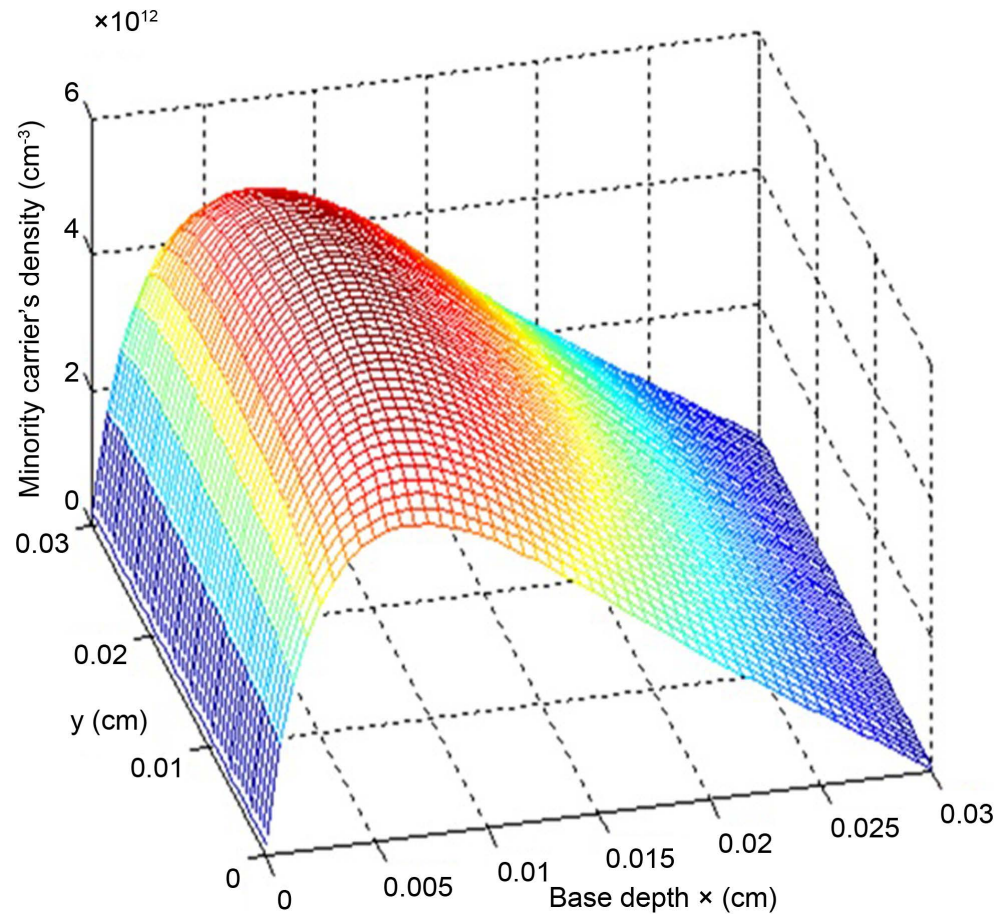

Figure 7. Minority carriers density front surface illumination: $D=26 \mathrm{~cm}^{2} / \mathrm{s}$; $L=0.01 \mathrm{~cm} ; S_{j}=10^{6} \mathrm{~cm} / \mathrm{s} ; S_{b}=10^{5} \mathrm{~cm} / \mathrm{s} ; S_{b g}=10^{3} \mathrm{~cm} / \mathrm{s}$.

excess minority carriers density as shown in these figures, represented according to the base depth and the grain width, respectively for $S_{g b}=0, S_{g b}=10^{3} \mathrm{~cm} / \mathrm{s}, S_{g b}=10^{4} \mathrm{~cm} / \mathrm{s}$ and $S_{g b}=10^{6} \mathrm{~cm} / \mathrm{s} . S_{j}$ and $S_{b}$ being fixed at $10^{6} \mathrm{~cm} / \mathrm{s}$ and $10^{5} \mathrm{~cm} / \mathrm{s}$. 


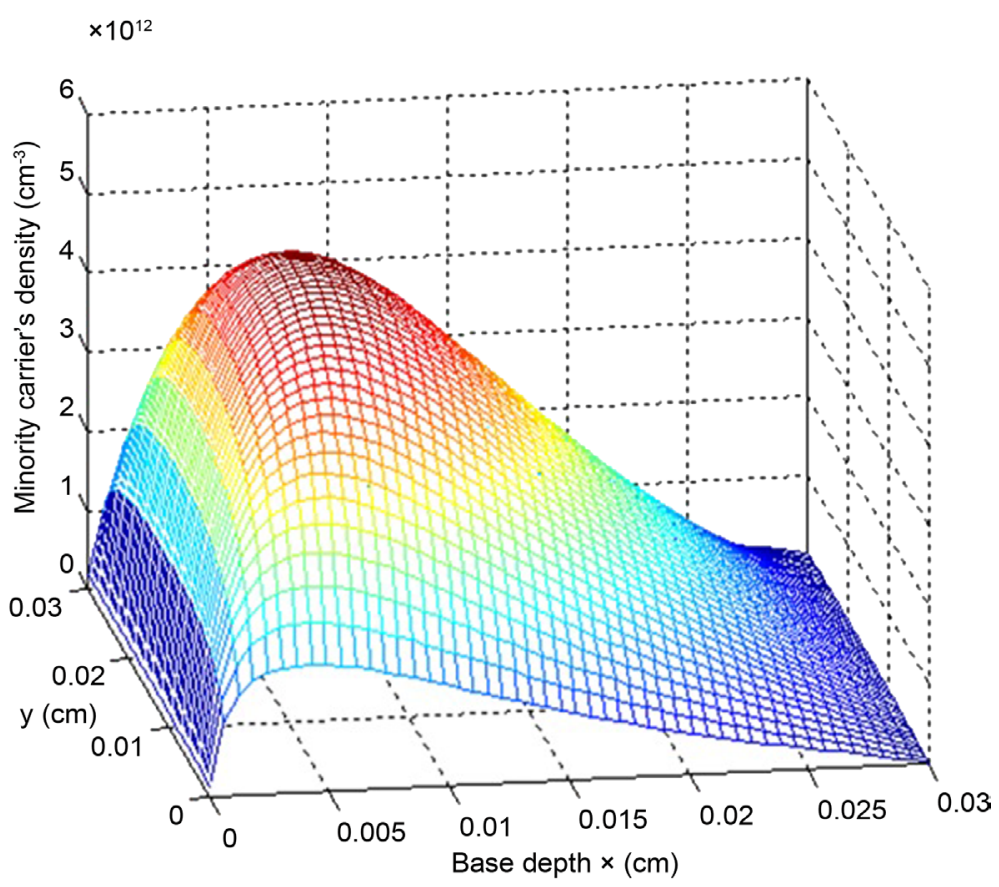

Figure 8. Minority carriers density front surface illumination: $D=26 \mathrm{~cm}^{2} / \mathrm{s}$; $L=0.01 \mathrm{~cm} ; S_{j}=10^{6} \mathrm{~cm} / \mathrm{s} ; S_{b}=10^{5} \mathrm{~cm} / \mathrm{s} ; S_{g b}=10^{4} \mathrm{~cm} / \mathrm{s}$.

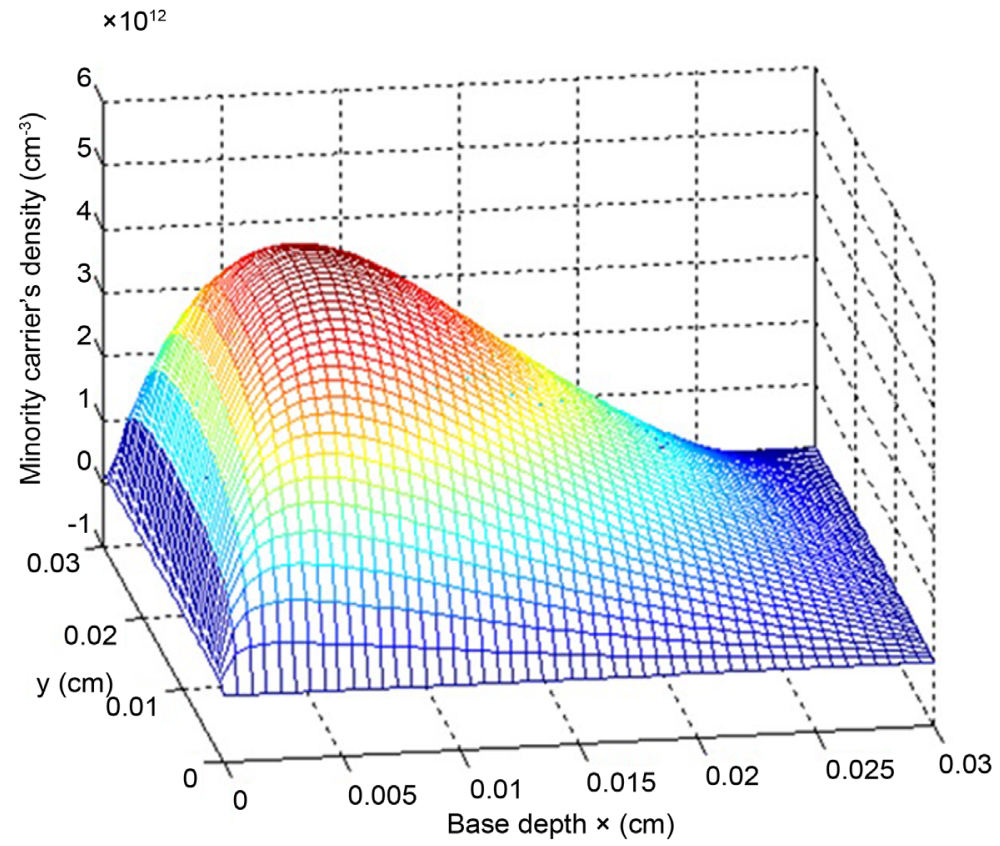

Figure 9. Minority carriers density front surface illumination: $D=26 \mathrm{~cm}^{2} / \mathrm{s}$; $L=0.01 \mathrm{~cm} ; S_{j}=10^{6} \mathrm{~cm} / \mathrm{s} ; S_{b}=10^{5} \mathrm{~cm} / \mathrm{s} ; S_{b g}=10^{6} \mathrm{~cm} / \mathrm{s}$.

When $S_{b g}=0$, there are no losses by recombination at the grains boundaries. The photogenerated carrier's density is more important. When $S_{g b}$ increases, the recombination becomes more important and the carrier's density decreases. We can note that at the grains boundaries (borders $y=0$ and $y=H_{2}$ ), the carriers density is weak. That is 
more and more remarkable when $S_{g b}$ increases [1].

When $S_{b g}$ reaches the value of $S_{j}=10^{6} \mathrm{~cm} / \mathrm{s}$, the carriers density becomes null at the boundaries.

Figure 10 and Figure 11 below represent the photogenereted minority carriers densities according to the base depth, with a boundary recombination velocity $S_{g b}=10^{5} \mathrm{~cm} / \mathrm{s}$, and the junction recombination velocity $S_{p}$ respectively equal to $10^{4} \mathrm{~cm} / \mathrm{s}$ and $10^{5} \mathrm{~cm} / \mathrm{s}$. The effects of $S_{j}$ are definitely observable on these curves. That permits us to note the

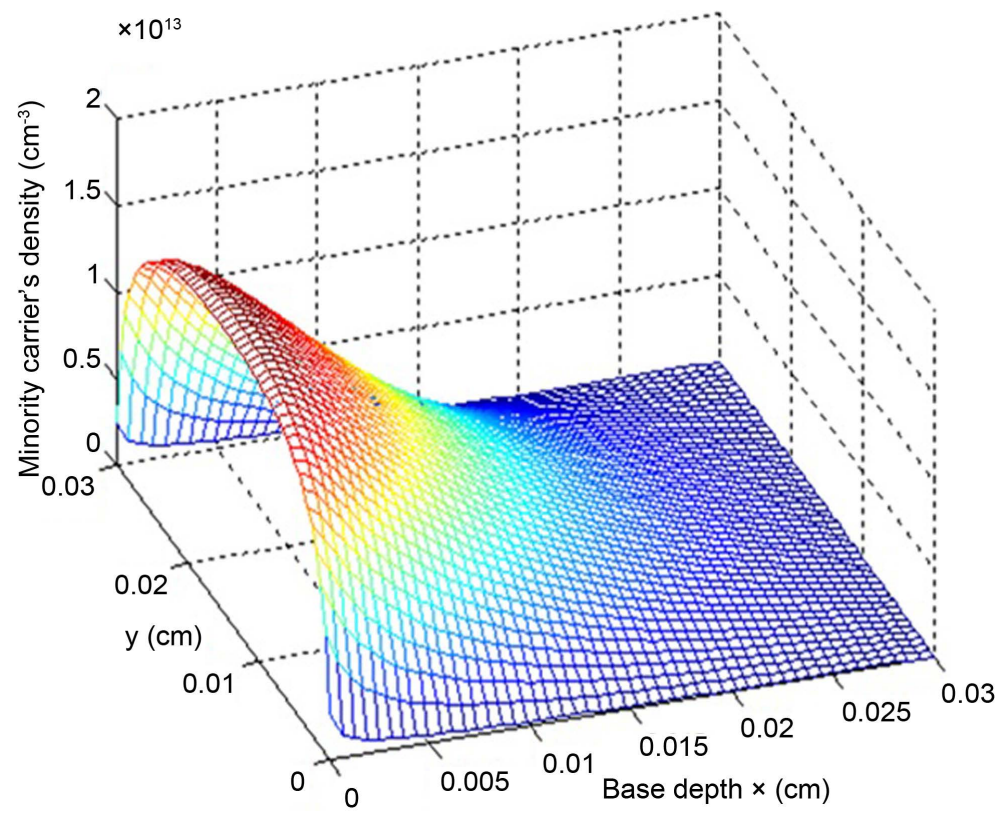

Figure 10. Minority carriers density front surface illumination: $D=26 \mathrm{~cm}^{2} / \mathrm{s}$; $L=0.01 \mathrm{~cm} ; S_{j}=10^{4} \mathrm{~cm} / \mathrm{s} ; S_{b}=10^{5} \mathrm{~cm} / \mathrm{s} ; S_{b g}=10^{5} \mathrm{~cm} / \mathrm{s}$.

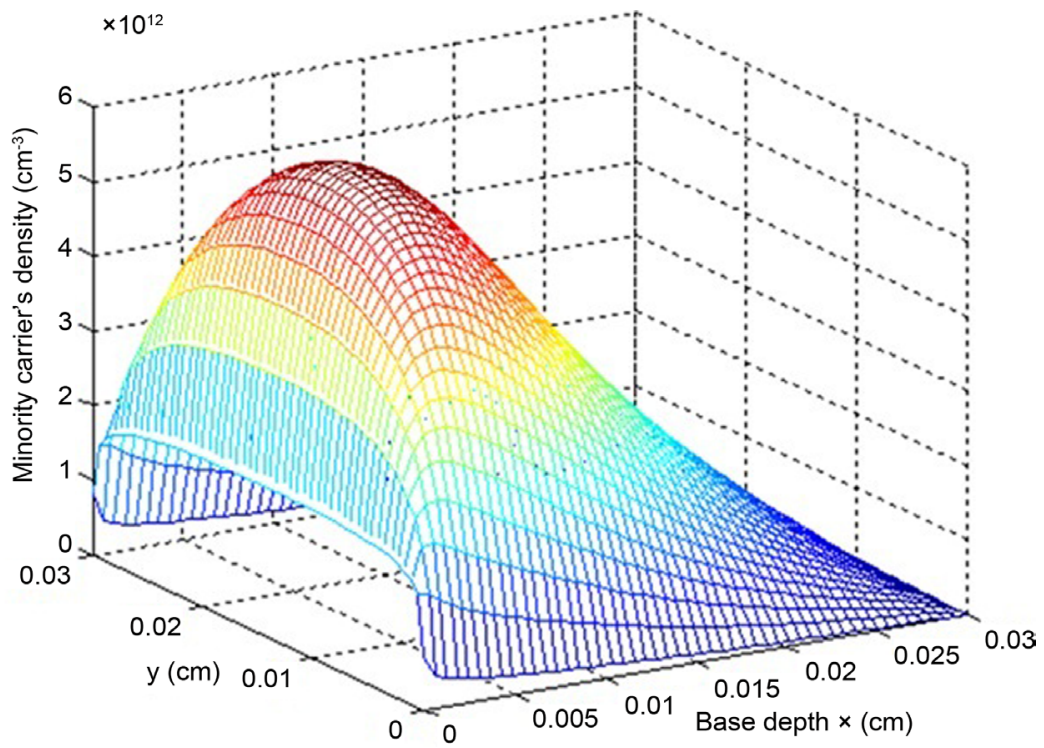

Figure 11. Minority carriers density front surface illumination: $D=26 \mathrm{~cm}^{2} / \mathrm{s} ; L=$ $0.01 \mathrm{~cm} ; S_{j}=10^{4} \mathrm{~cm} / \mathrm{s} ; S_{b}=10^{5} \mathrm{~cm} / \mathrm{s} ; S_{b g}=10^{5} \mathrm{~cm} / \mathrm{s}$. 
widening of the space charge region $\mathrm{Z}_{\mathrm{CE}}$ and the reduction, even the cancellation of the carriers density at $y=0$ and $y=H_{2}$ planes boundary. These profiles of the carrier's density permit to highlight the recombination phenomenon which is an important one in the solar cells operation [10].

The same effects are observed when the solar cell is illuminated on the back surface as illustrated in Figure 12 for the same value of $S_{b g}=10^{5} \mathrm{~cm} / \mathrm{s}$.

\subsection{Photocurrent Density}

The photocurrent density is determined starting from Equation (21). We have represented it in Figure 13, versus the junction recombination velocity $S_{p}$ for various values of $S_{g b}$.

As waited, when $S_{j}$ is equal to zero, the photocurrent density is null. When the junction recombination velocity $S_{j}$ increases, the photocurrent density increases and is saturated when $S_{j}$ reaches a critical value, corresponding to the short-circuit operation of the solar cell.

When the junction recombination velocity $S_{j}$ is close to zero, the photocurrent density is null. That corresponds to the open-circuit operation of the solar cell. While when $S_{j}$ is very large, the photocurrent density is constant and equal to the short-circuit current. We can also note that the open circuit or the short-circuit operation depends to the boundary recombination velocity $S_{g b}$. That is due to the fact that when $S_{g b}$ is higher, losses by recombination are important.

\subsection{Photovoltage}

The photovoltage is one of the characteristic elements of the solar cell. Using our numerical code, we have determined the photovoltage and represented it in Figure 14,

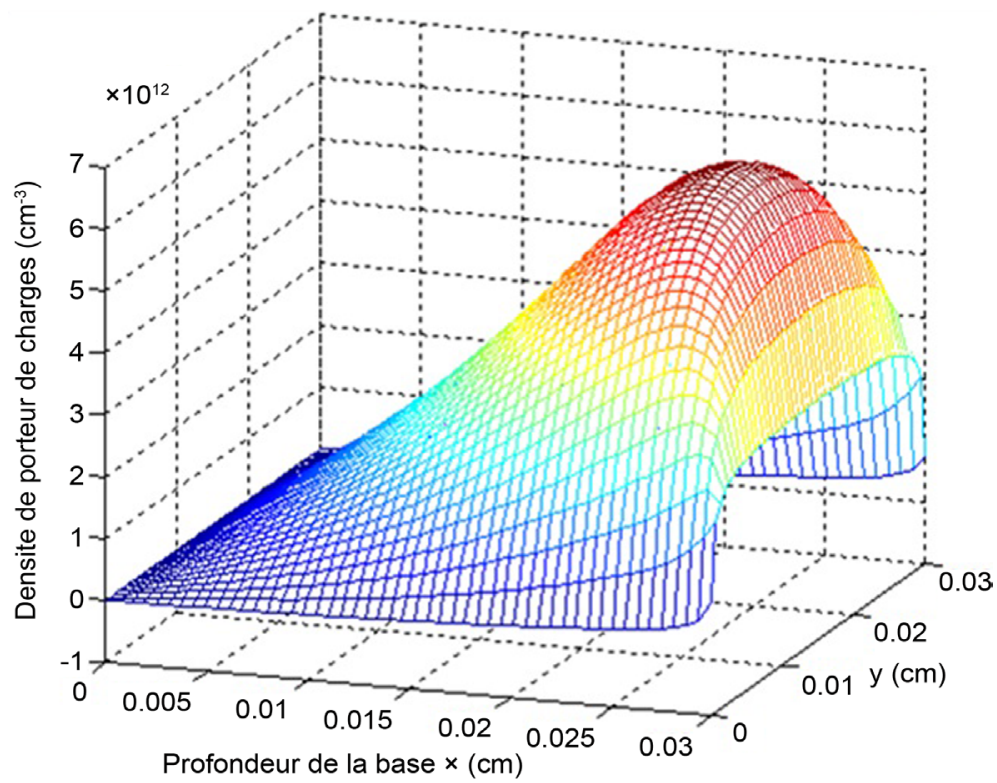

Figure 12. Minority carriers density back surface illumination: $D=26 \mathrm{~cm}^{2} / \mathrm{s}$; $L=0.01 \mathrm{~cm} ; N=30 ; S_{j}=10^{6} \mathrm{~cm} / \mathrm{s} ; S_{b}=10^{5} \mathrm{~cm} / \mathrm{s} ; S_{g b}=10^{5} \mathrm{~cm} / \mathrm{s}$. 


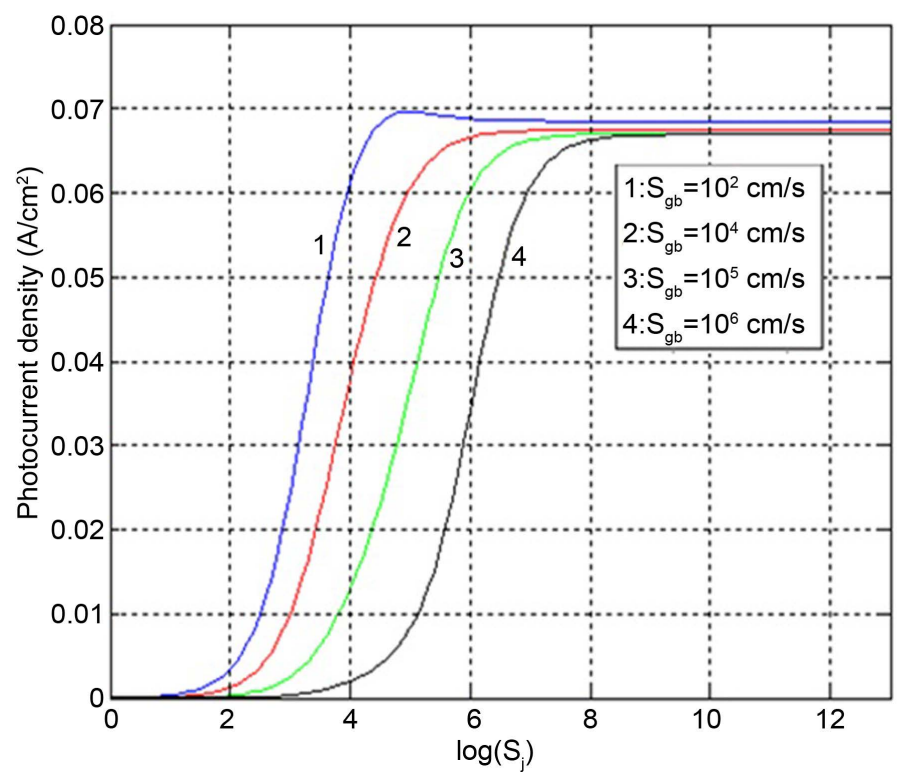

Figure 13. Photocurrent density, front surface illumination; effect to $S_{b g}: D=26$ $\mathrm{cm}^{2} / \mathrm{s} ; L=0.01 \mathrm{~cm} ; S_{b}=10^{2} \mathrm{~cm} / \mathrm{s}$.

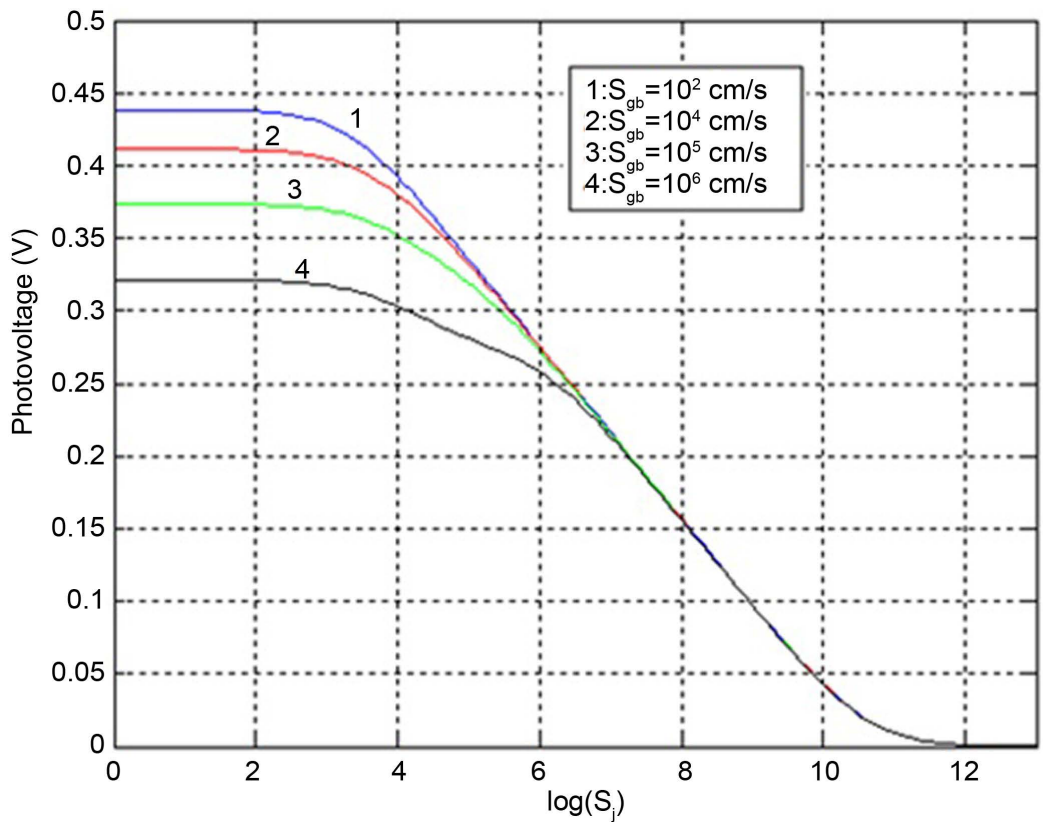

Figure 14. Photo tension front surface illumination: $D=26 \mathrm{~cm}^{2} / \mathrm{s} ; L=0.01 \mathrm{~cm}$; $S_{b}=10^{5} \mathrm{~cm} / \mathrm{s}$.

according to the junction recombination velocity for various values of $S_{g b}$. This figure shows that when the junction recombination velocity $S_{j}$ is close to zero, the photovoltage is equal to the circuit-open photovoltage $V c o$. and when $S_{j}$ increases from zero to approximately $S_{j}=10^{2} \mathrm{~cm} / \mathrm{s}$, the photovoltage remains constant and equal to the open circuit photovoltage. Beyond that value, the photovoltage decreases and cancels out when $S_{j}$ reaches the short-circuit operation, for a value of $S_{j}$ approximately equal to $10^{12}$ 
$\mathrm{cm} / \mathrm{s}$. We can also note that the open circuit photovoltage is larger when $S_{g b}$ is smaller.

\subsection{Current-Voltage Characteristics}

The knowledge of the current-voltage characteristic is very important for the solar cell characterization. Using our code of calculations, we have determined and represented in Figure 15, the current-voltage characteristics of the solar cell for various values of the grain boundaries recombination velocity $S_{g b}$.

As awaited, these characteristics are in conformity with the solar cell operation. Indeed, one notes that when the photovoltage is equal to zero, the photocurrent density is equal to the short-circuit photocurrent density Jcc. When the photovoltage increases, the photocurrent density decreases and cancels, when the photovoltage reaches the open circuit photovoltage $V c o$.

One can notice that the open circuit photovoltage $V c o$ and the short-circuit photocurrent density Jcc decrease when the grains boundaries recombination velocity $S_{g b}$ increases [1].

\section{Conclusions}

In this study we have realized a characterization of a polycrystalline silicon solar cell by the finite element method in $2 \mathrm{D}$, by highlighting the effects of grains boundaries recombination velocity, on the electrical parameters of the solar cell.

From this new approach, the polycrystalline solar cell has been modelled and the photogenered excess minority carrier's density has been determined. The characteristics of the solar cell (photocurrent density, photovoltage, and current-voltage) have been determined for various values of $S_{g b}$, highlighting the effects of the recombination at the grains boundaries on the solar cells operation.

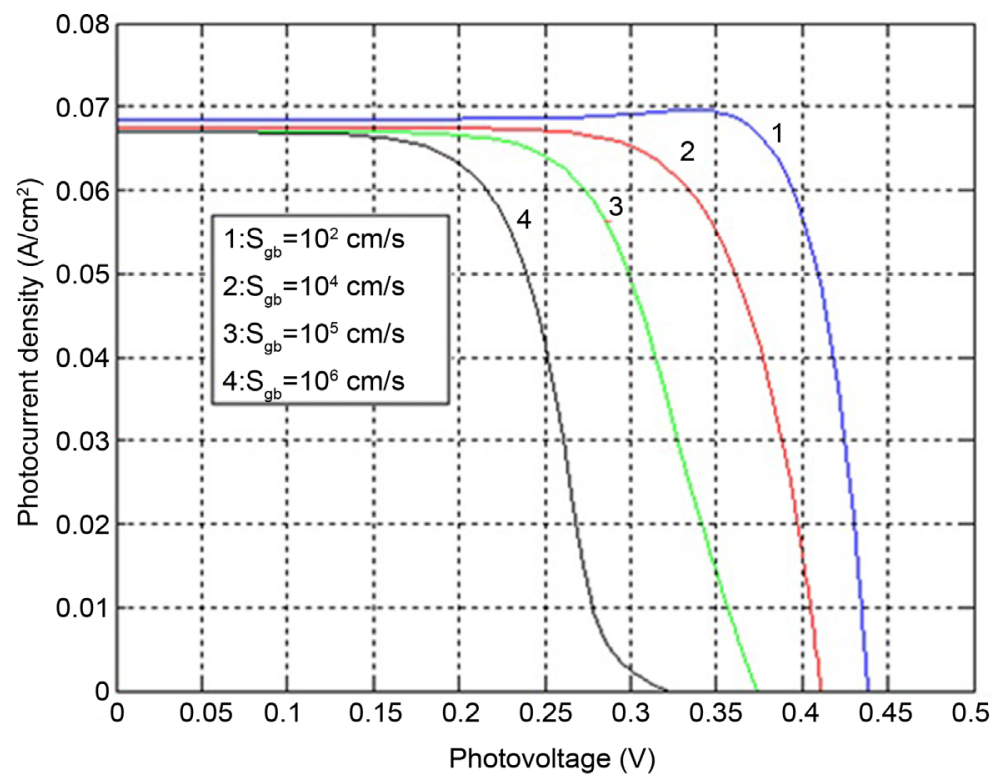

Figure 15. Current-voltage characteristics of the solar cell for various values of $S_{g b}$, front surface illumination. 
This approach based on a completely numerical method, permits to circumvent certain difficulties in the seeking of the solutions of equations which govern the solar cells operation.

\section{References}

[1] Gueye, S., Diallo, H.L., Ndiaye, M., Dione, M.M. and Sissoko, G. (2013) Effect of the Boundary Recombination Velocity and the Grain Size at the Phenomenological Parameters of the Monofacial Solar Cells under Multispectral Illumination in Steady State. International Journal of Emerging Technology and Advanced Engineering, 3, 1-8. www.ijetae.com

[2] Diaw, M., Zouma, B., Sere, A., Mbodji, S., Camara, A.G. and Sissoko, G. (2012) 3D Study to Improve the IQE of the Bifacial Polycrystalline Silicon Solar Cell from the Grain's Geometries and the Applied Magnetic Field. International Journal of Engineering Science and Technology (IJEST), 4, 3673.

[3] Dione, M.M., Ly, I., Diao, A., Gueye, S., Gueye, A., Thiame, M. and Sissoko, G. (2013) Determination of the Impact of the Grain Size and the Recombination Velocity at Grain Boundary on the Values of the Electrical Parameters of a Bifacial Polycristallin Silicon Solar Cell. IRACST-Engineering Science and Technology: An International Journal (ESTI), 3, 330-334.

[4] Diallo, H.L., Zoungrana, I.L., Nzonzolo, M., Barro, F.I. and Sissoko, G. (2006) 3D Modelling of a Polycrystalline Silicon Solar Cell under Constant White Bias Light: Effect of Grain Size and Grain Boundary on Recombination Parameters. 21 st European Photovoltaic Solar Energy Conference, 4-8 September 2006, Dresden, 451-454.

[5] Dieng, A., Thiam, N., Samb, M.L., Maiga, A.S., Barro, F.I. and Sissoko, G. (2009) Etude A 3d D’une Photopile Polycrystalline Au Silicium: Influence De La Taille De Grain Et De La Vitesse De Recombinaison Aux Joints De Grain Sur Les Paramètres Electriques. Journal des Sciences, 9, 51-63.

[6] Zoungrana, M., Zerbo, I., Barro, F.I., Sam, R., Touré, F., Samb, M.L. and Zougmoré, F. (2011) Modélisation à 3-D de l'influence de la taille des grains et de la vitesse de recombinaison aux joints de grain sur une photopile au silicium polycristallin sous éclairement concentré. Revue des Energies Renouvelables, 14, 649-664.

[7] Samb, M.L., Zoungrana, M., Sam, R., Dione, M.M., Deme, M.M. and Sissoko, G. (2010) Etude en Modélisation à 3-d d'une photopile au silicium en régime statique placée dans un champ Magnétique et sous éclairement Multispectral: Détermination des paramètres électriques. Journal des Sciences, 10, 23-38. http://www.cadjds.org

[8] Dia, F.S., Diasse, O., Sam, R.S., Diallo, H.L., Dieng, B., Thiam, N., Mbodji, S. and Sissoko, G. (2012) 1D Modeling Study of Series and Shunt Resistances of Silicon Solar Cell in Steady State Operating Condition and under Polychromatic Illumination. International Journal of Advanced Technology \& Engineering Research (IJATER), 2, 18-23.

[9] Nzonzolo, Lilonga-Boyenga, D. and Sissoko, G. (2014) Illumination Level Effects on Macroscopic Parameters of a Bifacial Solar Cell. Energy and Power Engineering, 6, 25-36. http://dx.doi.org/10.4236/epe.2014.63004 http://www.scirp.org/journal/epe,http://dx.doi.org/10.4236/epe.2014.63004

[10] Nzonzolo (2004) Recombination Parameters Determination from the Study of CurrentVoltage Characteristic of a Bifacial Solar Cell under Constant Ullimination. Doctorate Third Cycle, Cheikh Anta Diop University, Dakar.

[11] Daveau Christian cours méthodes des éléments finis 2010/2011: Université de CergyPontoise, Département de mathématique, 95302, Cergy-Pontoise, cedex France. 
[12] Matthew, N. and Sadiku, O. (2000) Numerical Techniques in Electromagnetics. 2nd Edition, Ch.6, ISBN 0-8493-1395-3, CRC Press LLC.

Submit or recommend next manuscript to SCIRP and we will provide best service for you:

Accepting pre-submission inquiries through Email, Facebook, LinkedIn, Twitter, etc. A wide selection of journals (inclusive of 9 subjects, more than 200 journals)

Providing 24-hour high-quality service

User-friendly online submission system

Fair and swift peer-review system

Efficient typesetting and proofreading procedure

Display of the result of downloads and visits, as well as the number of cited articles

Maximum dissemination of your research work

Submit your manuscript at: http://papersubmission.scirp.org/

Or contact cs@scirp.org 